\title{
A Suspicious Facial Lesion - A Unique Opportunity to Test the North Carolina Laboratory Response Network
}

\author{
Christopher, P.S., B.Tech.*, Saah, J.R., M.S.**, and Miller, S.E., Ph.D.*
}

* Department of Pathology, P.O. Box 3712, Duke University Medical Center, Durham, NC 27710 ** Bioterrorism and Emerging Pathogens Unit, North Carolina State Laboratory for Public Health, 306 N. Wilmington Street, Raleigh, NC 27601

In the mid 1990's, authorities recognized the potential of a bioterrorism attack on the US. The Laboratory Response Network (LRN) became operational in 1999 through collaboration among the Centers for Disease Control and Prevention (CDC), the Federal Bureau of Investigation (FBI), and the Association of Public Health Laboratories [1]. The LRN is responsible for establishing a network of national and international laboratories (federal, military, and state and local public health facilities) capable of performing confirmatory testing for high priority biological agents [2]. The assault on September 11, 2001 and the anthrax release a week later confirmed the reality of this threat [3].

To fulfill its LRN role, the North Carolina Division of Public Health established the Bioterrorism and Emerging Pathogens (BTEP) Unit in 2003. As well as testing suspected agents, this unit is responsible for coordinating the North Carolina LRN (NCLRN), comprised of employees of the state public health laboratory, inclucing members of the division's Communicable Disease Branch; hospital laboratory directors; and representatives from hospitals hosting public health epidemiologists. An intrastate communication network was also created, and algorithms for response to public health emergencies were devised. The NCLRN meets in a forum several times a year to share ideas on improving public health preparedness and strengthening our state's diagnostic capabilities.

The Duke Electron Microscopy Laboratory has been a member of the NCLRN since its inception because of our expertise in diagnosing viral pathogens using negative stain and thin section transmission electron microscopy (TEM). TEM has long been recognized as an effective method of identifying viruses [4]. For example, variola virus, a poxvirus that causes smallpox, can be rapidly identified and easily distinguished from varicella-zoster virus (VZV), a herpesvirus that causes chicken pox and shingles $[5,6]$; in contrast, symptoms and lesions in early VZV infection may be confused with those of smallpox.

As the NCLRN EM Laboratory, we recently received a request from a county health department via the BTEP Unit to examine a specimen from a sore on the chin of a 7 year old girl. Due to the fact that the family commercially raised goats, the lesion was suspected of being caused by orf virus, a parapoxvirus that commonly infects sheep, goats, and occasionally, humans who have contact with livestock. Instructions for sample collection were relayed by phone to the local nurse practicianer who visited the family, took digital pictures of the chin (Fig 1), and collected material from the lesion. Because the patient was 2 hours away from our medical center and there was no established mechanism for specimen transport, phone conversations, initiated by the BTEP Unit and carried out by members of the NCLRN, arranged for the specimen to be transported by a willing technician to our laboratory. 
A negative stain was made from the blister fluid (which appeared to be mostly blood); the blister cap and cells pelleted from the fluid were processed for thin section TEM. No viruses were observed in negative stains of the blister fluid, but many herpesviruses (Fig. 2) and numerous bacteria, both cocci and bacilli, replicating within cells were seen in thin sections of the blister cap. One of the reasons TEM is considered an important diagnostic tool in virology is that it has the ability to find the unexpected [4]; even if molecular tests had been available and had been run for the suspected orf virus, the results would have been negative. A poxvirus similar to orf virus is shown in Fig. 3 for comparison.

This activity provided a good test of the NCLRN communication network. It was a very useful exercise for our laboratory, as it tested our ability to function within the NCLRN and provided us with insight that may prove vital in a true public health emergency. It highlighted the facts that good communication between caregivers and the laboratory is important, that samples should be collected by trained personnel, and that all materials received should be processed for examination. The exercise also demonstrated the benefit of a network knowledgeable of diagnostic capabilities across the state. Because of quarterly meetings, members are able to put names with faces, and be aware of the various services and expertise available. Finally, personalizing the response team made it easier to design a way to deliver the unusual specimen to a specialized laboratory when no established mechanism existed.

\section{References}

[1] http://www.bt.cdc.gov/lrn/

[2] http://www.bt.cdc.gov/lrn/biological.asp

[3] H.C. Lane, J. LaMontagne, and A.S. Fauci. Nature Med. 7 (2001) 1272.

[4] P.R. Hazelton and H.R. Gelderblom. http://www.cdc.gov/ncidod/EID/vol9no3/02-0327.htm

[5] S.S. Biel and H.R. Gelderblom. J. Clin. Virol. 13 (1999) 105.

[6] S.E. Miller. J. Ultrastruc. Pathol. 27 (2003) 133.

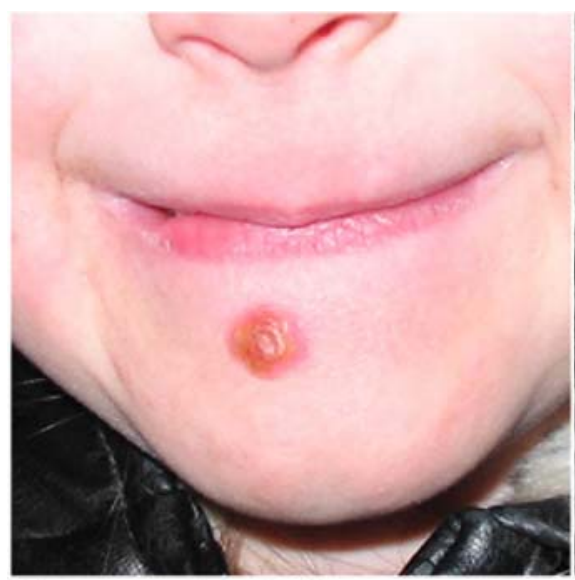

Figure 1. Chin lesion.

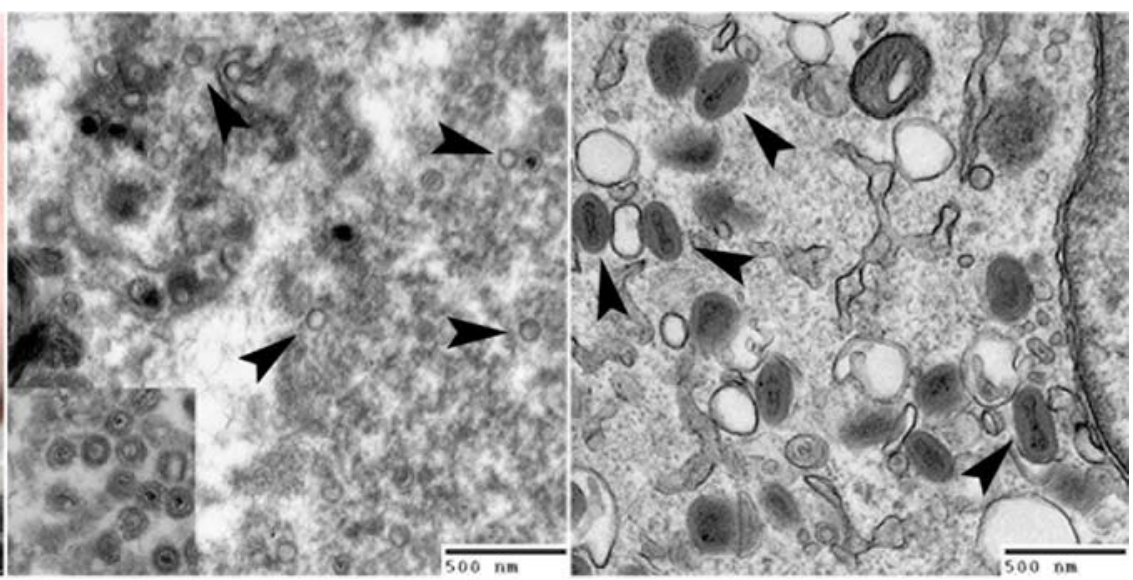

Figure 2. Herpesvirus found in Figure 3. Poxvirus (arrows) lesion; nucleocapsids (arrows). similar to suspected orf virus. Inset. Enveloped (complete) herpesvirus particles. 